\title{
Peritoneal Dialysis
}

\section{SUMMARY}

Peritoneal dialysis (PD) is a renal replacement therapy based on infusing a sterile solution into the peritoneal cavity through a catheter and provides for the removal of solutes and water using the peritoneal membrane as the exchange surface. This solution, which is in close contact with the capillaries in the peritoneum, allows diffusion solute transport and osmotic ultrafiltration water loss since it is hyperosmolar to plasma due to the addition of osmotic agents (most commonly glucose). Infusion and drainage of the solution into the peritoneal cavity can be performed in two ways: manually (continuous ambulatory PD), in which the patient usually goes through four solution changes throughout the day, or machine-assisted PD (automated PD), in which dialysis is performed with the aid of a cycling machine that allows changes to be made overnight while the patient is sleeping. Prescription and follow-up of PD involve characterizing the type of peritoneal transport and assessing the offered dialysis dose (solute clearance) as well as diagnosing and treating possible method-related complications (infectious and non-infectious).

KEYWORDS: Peritoneal Dialysis. Renal Replacement Therapy. End Stage Renal Disease. Chronic Kidney Failure.

\section{INTRODUCTION}

Individuals with stage $\mathrm{V}$ or terminal chronic kidney disease, which means those with a glomerular filtration rate $<15 \mathrm{~mL} / \mathrm{min} / 1.73 \mathrm{~m}^{2}$, will need some therapy to replace renal function ${ }^{1}$. This therapy can include kidney transplantation or one of the available dialysis modalities: hemodialysis (HD) or peritoneal dialysis (PD). Both forms of dialysis promote renal replacement by withdrawing solutes and water, restoring the electrolyte balance and correcting acidosis. However, unlike HD, which is based on blood passing through an extracorporeal circuit through a vascular access, PD involves the exchange of solutes and water between blood in the peritoneal capillaries and the instilled solution in the peritoneal cavity (dialysate) through a catheter, using the peritoneal membrane as the dialysing surface ${ }^{2}$. This dialysis solution is packaged in clear flexible plastic bags, and the patient or caregiver is trained by specialized nursing staff to connect these bags to the catheter through the sterile technique in their home or another appropriate environment (for example, their workplace).

One of the greatest advantages of PD is its portability, because as the treatment is provided by the patient or caregiver, there is greater freedom to travel and greater independence from medical and nursing staff compared to HD. Moreover, as it is a continuous therapy, PD constantly removes solutes and water, allowing for a less restrictive diet. Since it is a milder method, PD also provides greater preservation of residual renal function ${ }^{3}$. However, PD should be carried out daily, and the patient or caregiver is fully responsible for compliance with the prescription and paying

CORRESPONDING AUTHOR: Maria Claudia Cruz Andreoli

Rua Pedro de Toledo, 299 - Vila Clementino, São Paulo - Brasil - Postal Code 04039-030

E-mail: c.andreoli@uol.com.br 
attention to their technique to prevent infectious complications. Also, potential metabolic complications as well as structural changes in the peritoneal membrane can occur over time, which may compromise the effectiveness of the method, as will be seen later.

Absolute contraindications to PD are uncorrectable surgical conditions (e.g., extensive hernias, diaphragmatic hernias, or bladder exstrophy), loss of peritoneal function or multiple peritoneal adhesions and physical or mental inability to perform the method. Relative contraindications are the presence of abdominal vascular prostheses for less than four months, the presence of recent ventriculoperitoneal shunts, frequent episodes of diverticulitis, inflammatory or ischemic intestinal disease and morbid obesity ${ }^{4}$.

The peritoneum is a serous membrane with a surface of approximately 1 to $2 \mathrm{~m}^{2}$ in adults and has two leaflets, the visceral and the parietal. The structure of the peritoneal membrane is composed of a monolayer of mesothelial cells, the interstitium, peritoneal capillaries and visceral lymphatics ${ }^{5}$. The number of perfused capillaries determines the effective peritoneal surface area, which means the functional area available for exchanging between blood and the dial$y s^{2}{ }^{2}$. Capillaries represent the largest barrier to the transport of solutes and water. This transport can be explained by the three pore model: ultra-pores, small pores and large pores. The endothelial cells of peritoneal capillaries are permeable to water through ultrapores $(<0.5 \mathrm{~nm}$ radius). These transcellular pores are represented by endothelial cell membrane proteins called aquaporins. Small solutes and water are transported through intercellular slits called small pores (4 $\mathrm{nm}$ radius). In smaller numbers, large pores (12 to $15 \mathrm{~nm}$ radius) are sparsely distributed and responsible for the passive transport of macromolecules, such as albumin. Approximately $40 \%$ of ultrafiltration is believed to occur via solute-free transcellular pathways (aquaporins), and small pores are responsible for the transport of small solutes by diffusion and/ or convection ${ }^{6}$.

Solute movement occurs as a result of both diffusional and convective transport, while fluid removal occurs through the osmotic gradient created by the addition of osmotic agents to the dialysis solution. Solute diffusion primarily occurs by a concentration gradient, with solutes such as urea, creatinine and potassium moving from the plasma toward the dialysate, while other solutes, such as bicarbonate, usually move in the opposite direction.
Standard PD solutions contain high concentrations of glucose as an osmotic agent. This plasma hyperosmolar dialysate induces fluid removal from plasma, a process called ultrafiltration. The higher the ultrafiltration, the greater the convective transport of solutes. The volume of ultrafiltration depends on the glucose concentration in the dialysis solution used, the period of permanence of the fluid in the peritoneal cavity and the individual characteristics of each patient's peritoneal membrane, which we discuss below. With longer permanence periods, transperitoneal absorption of glucose leads to a decreased concentration of glucose in the dialysate, decreasing the osmotic gradient.

There is still a small amount of absorption of liquids, approximately $1 \mathrm{~mL} / \mathrm{min}$, and solutes through the lymphatic path.

\section{PERITONEAL ACCESS}

To perform PD, it is necessary to implant a catheter in the abdominal wall that will allow bidirectional flow of the dialysis solution. The catheter is a flexible silicone tube with multiple pores on its distal (intra-abdominal) portion, and it should ideally be positioned freely in the pelvic area. The most commonly used catheter is the Tenckhoff catheter, which has a straight configuration. The Tenckhoff catheter is laterally externalized through a hole called an exit point, and it has two Dacron cuffs. One of the cuffs is subcutaneous and 1 to $2 \mathrm{~cm}$ from the exit-site on the skin (external cuff), and the other cuff is near the peritoneum ${ }^{2}$.

Between catheter implantation and the beginning of dialysis therapy, it is advisable to wait at least two weeks ${ }^{7}$, a period called break-in, to prevent leakage of the pericatheter dialysate. In some cases, patients may require initiation of dialysis therapy immediately after catheter implantation; in these situations, only small volume exchanges are made, preferably in the supine position ${ }^{2}$.

\section{TYPES OF PD TREATMENT AND SOLUTIONS}

Chronic PD can be prescribed as follows:

Continuous Ambulatory Peritoneal Dialysis (CAPD): In this method, the peritoneal cavity is always filled with the dialysis solution (usually $2 \mathrm{~L}$ of solution), and this fluid is changed four times a day at 4-8 hour intervals (there may be variations, with infusions of 2-2.5 $\mathrm{L}$ and 3-5 changes per day in adults, according 
to the needs of each patient). This change is performed manually and occurs due to gravity through a system consisting of two bags connected by a Y-piece to the catheter. This two-bag system consists of an empty floor-standing bag to drain the solution from the peritoneal cavity (toxin saturated solution) and a fresh-solution bag that hangs on a stand at a height above catheter level to be infused immediately after draining the saturated solution (Figure 1). When connecting the system to the catheter, the patient first drains the solution that was left in the cavity for a few hours and then infuses the new solution. After this infusion, the patient disconnects the system and disposes it and is then free to perform activities until the next change.

Automated Peritoneal Dialysis (APD): Three to six changes are performed by an automatic cycler overnight while the patient is sleeping. APD can be of the following types:

Intermittent Night Peritoneal Dialysis: In this method, the patient makes the changes at night with the cycler, and the peritoneal cavity remains without dialysis fluid during the day. This method is generally indicated for patients who have residual renal function.

Continuous Cycling Peritoneal Dialysis: In addition to making the changes at night with the cycler, the patient maintains the dialysis solution within the peritoneal cavity during the day and may or may not perform manual changes during the day. This modality is performed by patients who do not have residual renal function ${ }^{8}$.

PD solutions come in 2 and $2.5 \mathrm{~L}$ plastic bags for use in CAPD and in $6 \mathrm{~L}$ bags for APD. The usual

FIGURE 1. SCHEME OF CONTINUOUS AMBULATORY PERITONEAL DIALYSIS (CAPD).

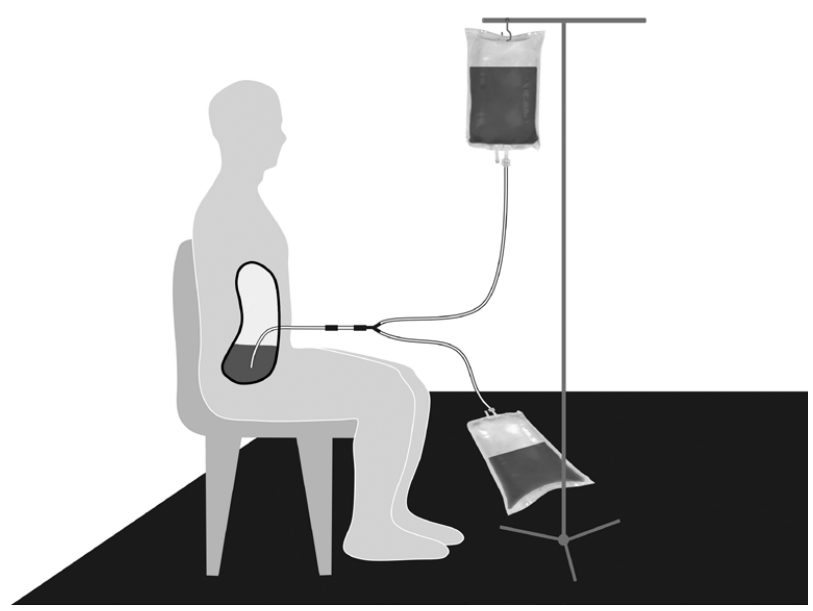

composition of the dialysis solution may vary according to the concentrations of glucose $(1.5 \%, 2.5 \%$ and $4.25 \%)$ and calcium $(2.5$ and $3.5 \mathrm{mEq} / \mathrm{L})$ and have a standard formulation for most suppliers (sodium 132 $\mathrm{mEq} / \mathrm{L}$, chlorine 95 to $102 \mathrm{mEq} / \mathrm{L}$ and lactate 35 to 40 $\mathrm{mEq} / \mathrm{L}$ ). The $\mathrm{pH}$ of the dialysis solution is low (5.5) to avoid glucose caramelization during heat sterilization. This low $\mathrm{pH}$ is generally well tolerated, but some patients may experience pain during infusion. This symptom is attributed to the low $\mathrm{pH}$ and hyperosmolarity of the solution. Typically, the solutions contain magnesium levels of 0.5 or $0.25 \mathrm{mM}$.

Glucose, which is used as an osmotic agent, has the advantage of being known, being relatively safe and inexpensive and being a source of calories, but also predisposes individuals to hyperglycaemia, dyslipidaemia, obesity and peritoneum damage in the long-term, either directly or through the products of glucose degradation. Another available osmotic agent is icodextrin, which is a high molecular weight glucose polymer.

Icodextrin is an iso-osmolar solution and induces ultrafiltration through its oncotic effect. As icodextrin is absorbed into the plasma through the lymphatic vessels, its absorption is much slower than that of glucose, and its associated oncotic effect and ultrafiltration are also more continuous than those of glucose ${ }^{9}$. Thus, icodextrin maintains the ultrafiltration capacity for several hours, and its main indications are the nocturnal permanence of CAPD and the daytime permanence of APD. Icodextrin is metabolised to maltose, maltotriose and other polysaccharides. As maltose can interfere with capillary blood glucose readings, leading to falsely elevated results, blood glucose monitoring in patients using icodextrin should be performed by specific devices (monitor and reagent strips) ${ }^{10}$. The icodextrin solution is available in Brasil.

\section{ADEQUACY IN PERITONEAL DIALYSIS}

The Guidelines of the International Society of Peritoneal Dialysis (ISPD) suggest that the adequacy of PD should be interpreted considering not only the adequate clearance of small solutes but should also include a clinical analysis that assesses quality of life, laboratory tests, nutritional aspects and appetite, volume status with adequate ultrafiltration to avoid volume overload, hemoglobin values, response to treatment with erythropoiesis stimulating medications, 
calcium and phosphorus metabolism, and blood pressure control ${ }^{11}$.

The clearance of small solutes is quantified using $\mathrm{Kt} / \mathrm{V}$, which is calculated according to the formula below and should be corrected for a body surface area of $1.73 \mathrm{~m}^{2}$ :

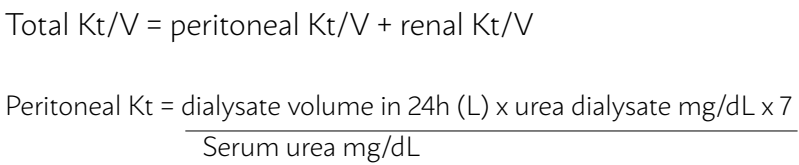

According to the National Kidney Foundation - Kidney Disease Outcomes Quality Initiative (NKF KDOQI) PD adequacy guideline, in patients with residual renal function, the minimum total $\mathrm{Kt} / \mathrm{V}$ dose (peritoneal + renal) should be at least 1.7 per week and should be evaluated at end of the first month of PD and every four months thereafter. Therefore, measures to preserve residual renal function should be taken, such as the use of angiotensin converting enzyme inhibitors or angiotensin II receptor blockers in hypertensive patients and avoidance of nephrotoxic drugs, such as nonsteroidal anti-inflammatory drugs, aminoglycosides and iodinated contrasts ${ }^{1}$.

For patients without residual renal function, the minimum offered dialysis dose should correspond to a peritoneal Kt/ $\mathrm{V}$ of at least 1.7 per week. The dose should be measured in the first month of therapy and every four months thereafter' 1 .

In patients who do not reach this $\mathrm{Kt} / \mathrm{V}$, the clearance of small molecules may be improved by increasing the number of changes and/or infusion volume, while the clearance of medium molecules is more dependent on the period the dialysate stays in contact with the peritoneal membrane. In APD patients, the dialysis dose can be improved by introducing the wet cavity during the day or even adding a change during the day.

In addition, another determinant of solute clearance that should be evaluated to better define the prescription of PD is the category or type of peritoneal transport of each patient, which is assessed by the peritoneal equilibrium test (PET).
By convention, the PET involves infusing $2 \mathrm{~L}$ of dialysate (D) at $2.5 \%$ glucose in the peritoneal cavity and collecting samples of this dialysate at 0,2 and 4 hours of permanence in the cavity. A plasma sample $(\mathrm{P})$ is also obtained mid-period (2 h). According to the creatinine $\mathrm{D} / \mathrm{P}$ ratio in the second and fourth hours, the glucose D/DO in the same period and the volume of dialysate drained after 4 hours, patients can be classified into one of four categories (Table 1). Considering peritoneal transport, it should be noted:

High transporters: They quickly reach a $\mathrm{D} / \mathrm{P}$ balance for creatinine and urea, but quickly absorb glucose with a rapid loss of osmotic gradients. They benefit from short-term changes.

Low transporters: Their creatinine $\mathrm{D} / \mathrm{P}$ balance is slower and incomplete, and the osmotic gradient remains longer. They need changes with a longer permanence period and greater volume per change.

\section{COMPLICATIONS IN PERITONEAL DIALYSIS}

\section{Pericatheter leak}

Break-in is the period between catheter implantation and the beginning of PD. Break-in is a prophylactic procedure that is used to prevent mechanical and infections complications, and a period of two weeks is recommended for patients starting elective PD. As for an unscheduled beginning of $\mathrm{PD}$, it is ideal to perform the therapy lying down and with a lower infusion volume $^{12}$. If there is a leakage of pericatheter peritoneal fluid, PD may be temporarily interrupted or the dialysis scheme can be changed to intermittent nightly dialysis. If the leakage does not resolve, the catheter should be replaced ${ }^{13}$.

\section{Drainage failure (Catheter dysfunction)}

Drainage failure occurs in two ways: the catheter infuses and does not drain, usually related to intestinal constipation, tip migration, or "sequestration of the omentum", or the catheter does not infuse and does not drain, which occurs due to folds and intramural obstruction ${ }^{13}$.

The recommended procedures are:

1) Check the catheter angle in the abdominal wall (tunnel): if there are folds, catheter replacement is required.

2) Intestinal constipation: correction with a laxative solves $50 \%$ of cases of drainage failure.

3) Fibrin (treatment): prophylactic heparin at a 
dose of $500 \mathrm{U} / \mathrm{L}$ is most commonly used; thrombolytic agents, such as alteplase, at a dilution of $1 \mathrm{mg} / \mathrm{mL}$ with a permanence of 2 to 4 hours can also be used ${ }^{14}$.

4) Catheter translocation: the tip of the catheter can be viewed through a simple abdominal X-ray. When observing catheter tip migration, some measures can be used, such as laxatives, flexible guidewire replacement (with or without radioscopy), and peritoneoscopy, or a catheter change can be performed. In some situations, the catheter tip is properly positioned and may be blocked by the omentum. In this situation, the treatment should be omentectomy and/ or omentopexy ${ }^{13}$.

\section{Hernias}

Hernias can occur in $10 \%$ to $25 \%$ of PD patients as a result of increased intra-abdominal pressure and most often require surgical correction. There are potential risk factors, such as the volume infused, recent surgery, obesity and polycystic kidney disease ${ }^{15}$. If the patient has residual renal function, corrective surgery can be performed without interruption of therapy. As a result, PD can be resumed one or two days after surgery, initially with a lower volume of infusion ${ }^{16}$.

\section{Hydrothorax}

Hydrothorax is a rare complication that occurs through passage of the dialysate into the pleural space via lymphatics or through a congenital diaphragmatic defect. The diagnosis is made by pleural fluid analysis, which reveals high concentrations of glucose and low concentrations of protein; technetium scintigraphy and contrast-enhanced tomography in the peritoneal cavity may be used. Treatment consists of discontinuation of dialysis for two to six weeks and measures to decrease intra-abdominal pressure, such as converting from CAPD to nocturnal APD with a dry peritoneal cavity during the day. If there is no improvement, pleurodesis, surgical repair and even method transfer may be necessary ${ }^{17}$.

\section{Edema and ultrafiltration failure}

Hypervolemia is an independent risk factor for cardiovascular disease and death in dialysis patients, and it is associated with ventricular hypertrophy, nutritional alterations and inflammation ${ }^{18}$. The causes of hypervolemia in PD are excessive salt and water intake, loss of residual renal function, non-adherence to dialysis prescription, excessive absorption of dialysate during a long change, low use of a hypertonic solution, mechanical complications (dysfunctional catheter, leaks), discrepancy between dialysis prescription and patient PET, and ultrafiltration failure (UFF).

For patients with a reduced ultrafiltration volume, the reversible causes should be assessed, such as an inappropriate dialysis prescription (period of permanence and concentration of the bags), and ruled out to solve mechanical complications ${ }^{19}$.

UFF is defined by the four rule - ultrafiltration lower than $400 \mathrm{~mL}$ after 4 hours of permanence with a $4.25 \%$ bag. After evaluating UFF, evaluate the membrane with the PET.

UFF is rated with the aid of the PET:

- Reduced ultrafiltration volume - fast solute transport: Type I UFF, which may be an intrinsic or acquired condition (e.g., after peritonitis, long time in PD) and results from osmotic gradient dissipation due to absorption of glucose into circulation.

- Reduced ultrafiltration volume - reduced solute transport: Type II UFF. The usual cause is a decrease in the effective peritoneal surface for exchange mainly due to fibrosis.

- Reduced ultrafiltration volume - normal solute transport: There are two possibilities. Type III UFF, when there is increased absorption of the direct peritoneal dialysate, especially lymphatics, or a functional deficit of aquaporins (ultra-small pores).

Treatment of UFF:

- Type I: avoid long periods of permanence or use icodextrin; a resting period for the peritoneum;

- Type II: difficult handling - change of dialysis method;

- Type III: optimize ultrafiltration with an increased glucose concentration, use lower exchange volumes and a shorter permanence; icodextrin ${ }^{20}$.

Weight gain, hypertriglyceridemia and hyperglycaemia

Due to the absorption of dialysate glucose, a caloric overload with a consequent weight gain, hypertriglyceridemia and hyperglycaemia can occur. Treatment includes a low calorie diet, increased physical activity and restricted water intake, seeking to minimize the need for hypertonic bags. The use of renal function-corrected dose fibrates is a therapeutic option for hypertriglyceridemia. Hyperglycaemia may require an oral hypoglycaemic adjustment and/ or insulin adjustment. If no improvement is obtained, 
consider changing the dialysis method.

\section{Encapsulating peritoneal sclerosis}

Encapsulating peritoneal sclerosis is a rare complication of long-term PD patients that is associated with high morbidity and mortality, usually due to an intestinal obstruction and malnutrition. There are no well-defined diagnostic criteria, and diagnosis is based on structural and functional characteristics, such as the combination of intestinal obstruction and peritoneal fibrosis encapsulation characteristics ${ }^{21}$. Anorexia, nausea, vomiting and weight loss are common, as well as anemia and hypoalbuminemia. Encapsulating peritoneal sclerosis can also present as hemoperitoneum and recurrent sterile peritonitis. Laparotomy is the only way to make a definitive diagnosis, but it is not usually performed due to its high risk. Computed tomography findings include variable bowel loop diameters, dilated and adhered loops, septate ascites, calcification, and thickening of the intestinal wall and peritoneal membrane. In addition to providing nutritional support (usually parenteral), PD should be discontinued. Corticosteroids, tamoxifen and immunosuppression have been described as alternative therapies, but these are of inconclusive benefit. Surgical treatment can also be tried as a treatment ${ }^{22}$.

\section{Infectious complications}

- Peritonitis: This is the most serious complication of $\mathrm{PD}$ and is still the main factor for the failure of the technique. PD patients with abdominal pain should always have the diagnosis of peritonitis ruled out. Abdominal pain, turbid dialysis fluid and a peritoneal reaction are symptoms that may be encountered, which are confirmed by a dialysate cell count greater than 100 leukocytes $/ \mu \mathrm{L}$, with a predominance of at

TABLE 1. CLASSIFICATION BY TYPE OF PERITONEAL TRANSPORT

\begin{tabular}{l|l|l|l} 
Category & \multicolumn{1}{c}{$\begin{array}{l}\text { D/P Cre- } \\
\text { atinine }\end{array}$} & \multicolumn{1}{c}{$\begin{array}{l}\text { D/D0 } \\
\text { Glucose }\end{array}$} & \multicolumn{1}{l}{$\begin{array}{l}\text { Drained Volume } \\
\text { 4h }\end{array}$} \\
\hline High transporter & $>0.81$ & $<0.26$ & $1,580-2,085 \mathrm{ml}$ \\
\hline $\begin{array}{l}\text { Medium-high } \\
\text { transporter }\end{array}$ & $0.65-0.81$ & $0.26-0.38$ & $2,085-2,368 \mathrm{ml}$ \\
\hline $\begin{array}{l}\text { Medium-low } \\
\text { transporter }\end{array}$ & $0.50-0.65$ & $0.38-0.49$ & $2,368-2,650 \mathrm{ml}$ \\
\hline Low transporter & $<0.50$ & $>0.49$ & $2,650-3,226 \mathrm{ml}$ \\
\hline
\end{tabular}

D/P creatinine: relationship between dialysate creatinine and plasma creatinine.D/DO glucose: relationship between the dialysate glucose concentration after 4 hours (D) and at time zero (DO) least $50 \%$ polymorphonuclear cells. The dialysate culture establishes the type of organism that causes the process, but it is not advisable to wait for its result to start treatment, which can be performed with intraperitoneal (IP) or systemic antibiotics for 14 to 28 days, depending on the organism in question, with doses corrected for renal function. The IP route is preferable. Repeated infections of the peritoneal cavity lead to a decrease in the area of exchange of the peritoneal membrane, with a consequent decrease in the effectiveness of dialysis treatment.

Treatment with gram-positive and gram-negative coverage should be initiated soon after peritoneal fluid culture collection. The ISPD recommends antibiotic selection be performed considering the local history of sensitivities to agents. Thus, a first-generation cephalosporin or vancomycin (gram-positive coverage) combined with a third-generation cephalosporin or aminoglycoside (gram-negative coverage) can be chosen. Antibiotics administered via the IP route may be given continuously (at all dialysis changes) or intermittently (once a day; in this case, the antibiotic bag should remain in the cavity for at least 6 hours). Dose recommendations are provided in Table 2. After identification of the agent through the culture results, the antibiotic should be adjusted (for example, once a gram-positive agent is identified, gram-negative coverage is suspended). Treatment may be outpatient, provided that the patient has no impairment of their general condition or signs of a systemic infection. The main treatment is a follow-up with the improvement of symptoms and, mainly, with clearing of the effluent; if there is no response after five days of appropriate treatment, refractory peritonitis is diagnosed, which requires catheter removal and transfer to HD.

TABLE 2. INTRAPERITONEAL ANTIBIOTIC DOSE RECOMMENDATIONS IN CAPDA

\begin{tabular}{l|l|l}
\multicolumn{2}{c}{$\begin{array}{l}\text { Intermittent } \\
\text { (per change, once } \\
\text { a day) }\end{array}$} & $\begin{array}{l}\text { Continuous (mg/L; } \\
\text { all changes) }\end{array}$ \\
\hline Amikacin & $2 \mathrm{mg} / \mathrm{kg}$ & AD 25; MD 12 \\
\hline Cefazolin or Cefalotin & $15 \mathrm{mg} / \mathrm{kg}$ & AD 500; MD 125 \\
\hline Ceftazidime & $1,000-1,500 \mathrm{mg}$ & AD 500; MD 125 \\
\hline Vancomycin & $\begin{array}{l}15-30 \mathrm{mg} / \mathrm{kg} \text { every } \\
5-7 \text { days }\end{array}$ & AD 1000; MD 25 \\
\hline $\begin{array}{l}\text { AD: attack dose; DM: maintenance dose. a. In patients with residual renal function } \\
\text { (defined as urine output }>100 \mathrm{~mL} / \text { day), antibiotic doses should be increased empiri- } \\
\text { cally by 25\%. Adapted from Li et al23. }\end{array}$
\end{tabular}


Peritonitis is considered recurrent when it occurs within four weeks after the end of antibiotic therapy for a previous episode, with isolation of the same agent or with a sterile culture. In this case, catheter replacement, which can be performed in a single procedure (simultaneous removal and implantation of another catheter), is recommended, provided that the effluent is clear.

In cases of Staphylococcus aureus (S. aureus) peritonitis, treatment for 21 days is suggested; for cases of Pseudomonas aeruginosa (P. aeruginosa) peritonitis, association with a second antipseudomonal agent, such as oral (PO) ciprofloxacin, an aminoglycoside or ceftazidime IP, is suggested. In such cases, the duration of treatment should be 21 to 28 days. In cases of fungal peritonitis, the catheter should be immediately removed and the antifungal agent maintained for at least two weeks after catheter removal.

After catheter removal due to infection and consequent transfer to HD, a minimum period of two to three weeks should elapse before reinsertion of a new PD catheter ${ }^{23}$.

- Catheter infection (at the exit-site on the skin or subcutaneous tunnel): Infection of the catheter outlet is diagnosed by the presence of local hyperaemia and exudate. The two main aetiological agents are $S$. aureus and $P$. aeruginosa. If an infection is suspected, take a swab culture and initiate treatment to prevent peritonitis. Additionally, topical antibiotics in the catheter outlet, such as mupirocin, are recommended to prevent infection. Treatment should be started with PO antibiotic therapy for at least 14 days. An empirical treatment should always provide coverage for $S$. aureus (e.g. cephalexin $500 \mathrm{mg}$ PO every 12 hours or every 8 hours), and in patients with a history of an exit-site infection with $P$. aeruginosa, it is recommended to use an antibiotic with antipseudomonal action (e.g., ciprofloxacin $250 \mathrm{mg}$ PO every 12 hours). In cases of a recurrent or slowly resolving $P$. aeruginosa infection, a second agent, such as an aminoglycoside or ceftazidime IP, may be added. Treatment should generally last for 14 days. If prolonged therapy with adequate antibiotic therapy is not sufficient to resolve the infection, catheter replacement in a single procedure (simultaneous removal and implantation of another catheter) under antibiotic coverage is recommended ${ }^{23}$.

\section{TECHNIQUE FAILURE}

In some situations, it is necessary to change the dialysis method from PD to HD. In these cases, we state that the technique failed. Failure can happen in the following cases:

1) When it is not possible to reach the ideal Kt/V urea. In such cases, patients should be informed of the risks of remaining on PD with an adequacy level below that recommended by the physician.

2) Low fluid removal in patients without residual renal function.

3) High transporter patients who have inadequate ultrafiltration and/or excessive protein loss (relative contraindication, obviously discovered after initiation and first PET).

4) Development of severe hypertriglyceridemia.

5) Frequent peritonitis.

6) Development of technical/mechanical problems.

7) Severe malnutrition resistant to aggressive treatment (relative).

\section{Authors' contribution}

The authors have contributed equally in drafting and reviewing the text.

\section{RESUMO}

A diálise peritoneal (DP) é uma terapia renal substitutiva baseada na infusão de uma solução estéril na cavidade peritoneal através de um cateter, proporcionando a remoção de solutos e água usando a membrana peritoneal como superfície de troca. Essa solução, em contato com os capilares do peritônio, permite o transporte difuso de solutos e a perda de água por ultrafiltração osmótica, uma vez que é hiperosmolar ao plasma devido à adição de agentes osmóticos (normalmente, a glicose). A infusão e drenagem da solução dentro da cavidade peritoneal pode ser realizada de duas maneiras: manualmente (DP ambulatorial contínua), em que o paciente, geralmente, passa por quatro trocas de solução durante o dia, ou por DP mecânica (automatizada), em que a diálise é realizada com o auxílio de uma máquina de diálise que permite que as trocas sejam feitas durante a noite, enquanto o paciente está dormindo. A prescrição e o acompanhamento da DP envolvem a caracterização do tipo de transporte peritoneal e a avaliação da dose de diálise oferecida (depuração do soluto), bem como o diagnóstico e tratamento de possíveis complicações relacionadas ao método (infecciosas e não infecciosas).

PALAVRAS-CHAVE: Diálise peritoneal. Terapia renal substitutiva. Doença renal crônica terminal. Insuficiência renal crônica. 


\section{REFERENCES}

1. Clinical practice guidelines for peritoneal dialysis adequacy. Am J Kidney Dis. 2006;48 Suppl 1:S98-129.

2. Manfredi SR, Nadaletto MAI, Draibe SA, Canziani MEF. Técnicas Dialíticas na Doença Renal Crônica. In: Guias de Medicina Ambulatorial e Hospitalar da UNIFESP-EPM: Nefrologia, 3th edition, edited by Ajzen $\mathrm{H}$, Schor N, Manole, Barueri, SP. 2011:449-59.

3. Moist LM, Port FK, Orzol SM, Young EW, Ostbye T, Wolfe RA, et al. Predictors of loss of residual renal function among new dialysis patients. I Am Soc Nephrol. 2000;11(3):556-64.

4. Oliver M|, Quinn RR. Selecting Peritoneal Dialysis in the Older Dialysis Population. Perit Dial Int. 2015;35(6):618-21.

5. Blake PG, Daugirdas JT. Physiology of Peritoneal Dialysis. In: Handbook of Dialysis, 5th edition, edited by Daugirdas JT, Blake PG, Ing TS, Lippincott Williams \& Wilkins, Philadelphia. 2015:392-407.

6. Bansal S, Teitelbaum I. Causes, Diagnosis, and Treatment of Peritoneal Membrane Failure. In: Principles and Practice of Dialysis, 5th edition, edited by Lerma EV, Weir MR, Lippincott Williams \& Wilkins, Philadelphia.2017:194-219

7. Figueiredo A, Goh BL, Jenkins S, Johnson DW, Mactier R, Ramalakshmi $\mathrm{S}$, et al. Clinical practice guidelines for peritoneal access. Perit Dial Int. 2010;30(4):424-9.

8. Dombros N, Dratwa M, Feriani M, Gokal R, Heimburger O, Krediet R, et al. European best practice guidelines for peritoneal dialysis. 2 The initiation of dialysis. Nephrol Dial Transplant. 2005;20 Suppl 9:ix3-ix7.

9. Finkelstein F, Healy H, Abu-Alfa A, Ahmad S, Brown F, Gehr T, et al. Superiority of icodextrin compared with $4.25 \%$ dextrose for peritoneal ultrafiltration. . Am Soc Nephrol. 2005;16(2):546-54.

10. Diaz-Buxo |A, Passlick-Deetjen |, Gotloib L. Potential hazards of polyglucose. ASAIO J. 2001;47(6):602-7.

11. Lo WK, Bargman JM, Burkart J, Krediet RT, Pollock C, Kawanishi H, et al. Guideline on targets for solute and fluid removal in adult patients on chronic peritoneal dialysis. Perit Dial Int. 2006;26(5):520-2.
12. Crabtree $J H$, Shrestha BM, Chow KM, Figueiredo AE, Povlsen JV, Wilkie M, et al. Creating and Maintaining Optimal Peritoneal Dialysis Access in the Adult Patient: 2019 Update. Perit Dial Int. 2019.

13. Bender FH. Avoiding harm in peritoneal dialysis patients. Adv Chronic Kidney Dis. 2012;19(3):171-8.

14. Krishnan RG, Moghal NE. Tissue plasminogen activator for blocked peritoneal dialysis catheters. Pediatr Nephrol. 2006;21(2):300.

15. Del Peso G, Bajo MA, Costero O, Hevia C, Gil F, Diaz C, et al. Risk factors for abdominal wall complications in peritoneal dialysis patients. Perit Dial Int. 2003;23(3):249-54.

16. Bargman |M. Hernias in peritoneal dialysis patients: limiting occurrence and recurrence. Perit Dial Int. 2008;28(4):349-51.

17. Lew SQ. Hydrothorax: pleural effusion associated with peritoneal dialysis. Perit Dial Int. 2010;30(1):13-8.

18. Aguiar PV, Santos O, Teixeira L, Silva F, Azevedo P, Vidinha J, et al. Overhydration prevalence in peritoneal dialysis - A 2 year longitudinal analysis. Nefrologia. 2015;35(2):189-96

19. Mujais S, Nolph K, Gokal R, Blake P, Burkart |, Coles G, et al. Evaluation and management of ultrafiltration problems in peritoneal dialysis. International Society for Peritoneal Dialysis Ad Hoc Committee on Ultrafiltration Management in Peritoneal Dialysis. Perit Dial Int. 2000;20 Supp 4:S5-21.

20. Boudville N, Blake PG. Volume Status and Fluid Overload in Peritoneal Dialysis. In: Handbook of Dialysis, 5th edition, edited by Daugirdas JT, Blake PG, Ing TS, Lippincott Williams \& Wilkins, Philadelphia. 2015:483-9.

21. Brown EA, Bargman J, van Biesen W, Chang MY, Finkelstein FO, Hurst $\mathrm{H}$, et al. Length of Time on Peritoneal Dialysis and Encapsulating Peritoneal Sclerosis - Position Paper for ISPD: 2017 Update. Perit Dial Int. 2017;37(4):362-74

22. Cestari AT, Conti ML, Prats JA, Sato Junior H, Abensur H. [Sclerosing encapsulating peritonitis after peritoneal dialysis]. J Bras Nefrol. 2013;35(1):65-8.

23. Li PK, Szeto CC, Piraino B, de Arteaga J, Fan S, Figueiredo AE, et al. ISPD Peritonitis Recommendations: 2016 Update on Prevention and Treatment. Perit Dial Int. 2016;36(5):481-508. 